\section{Endoscopic ultrasound diagnosis of pneumatosis cystoides coli initially misdiagnosed as colonic polyps}

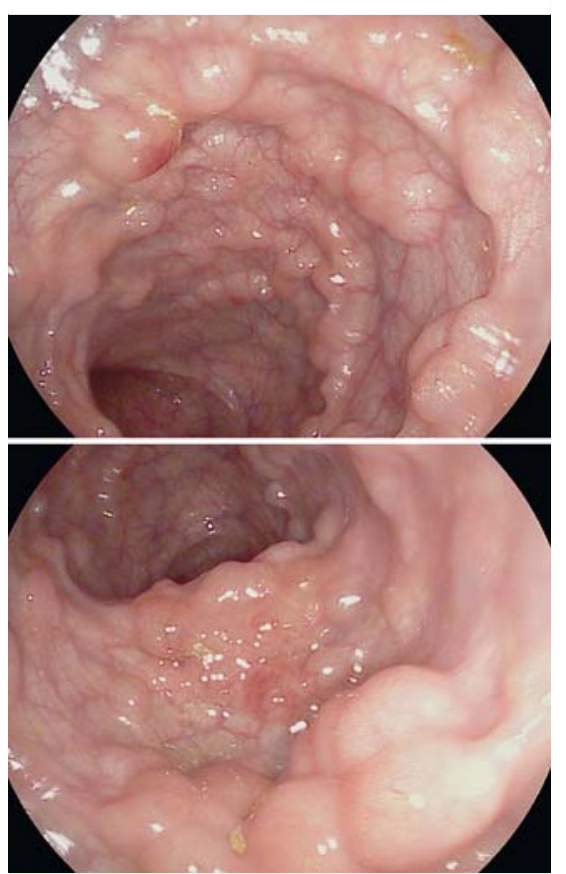

Fig. 1 Colonoscopic views showing multiple interconnected polyp-like lesions with normal overlying colonic mucosa.
An 85-year-old lady with chronic abdominal pain underwent a colonoscopy, which showed flat, spreading polypoidal lesions in the descending colon, and she was consequently referred for endoscopic mucosal resection (EMR). A repeat colonoscopy (Pentax EC 38-i10L) demonstrated multiple polypoidal lesions of varying sizes $(3 \mathrm{~mm}-3 \mathrm{~cm})$, which were apparently interconnected, in the descending colon ( Fig. 1; Video 1 ). The mucosa was of normal appearance on white-light endoscopy and also on i-scan with a Kudo's pit pattern type I. These features raised the suspicion of pneumatosis cystoides coli (PCC) and a radial endoscopic ultrasound (EUS; Pentax EG 3670 URK) confirmed this by showing multiple hyperechoic air pockets in the third wall layer of the descending colon ( Fig. 2; - Video2). A computed tomography (CT) scan performed to rule out other malignant disease subsequently also demonstrated air-filled cysts in the wall of the colon ( $\bullet$ Fig. 3 ).

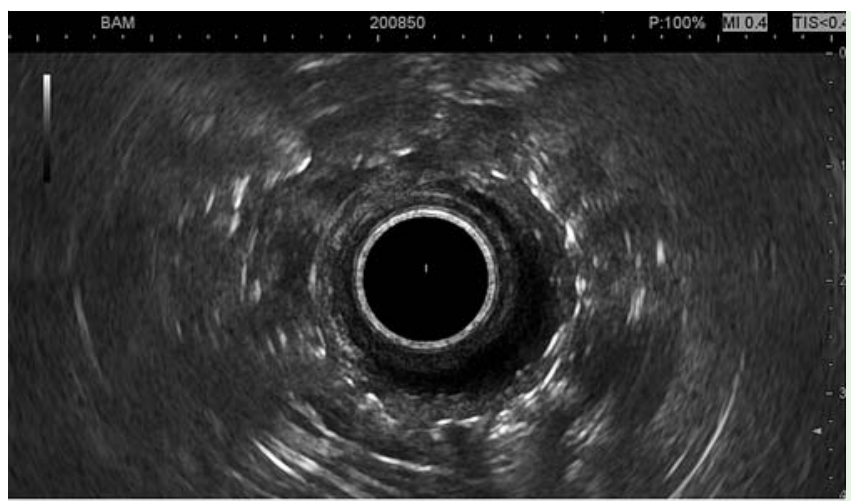

Fig. 2 Radial endoscopic ultrasound (EUS) views showing hyperechoic air pockets in the third layer of the colonic wall.

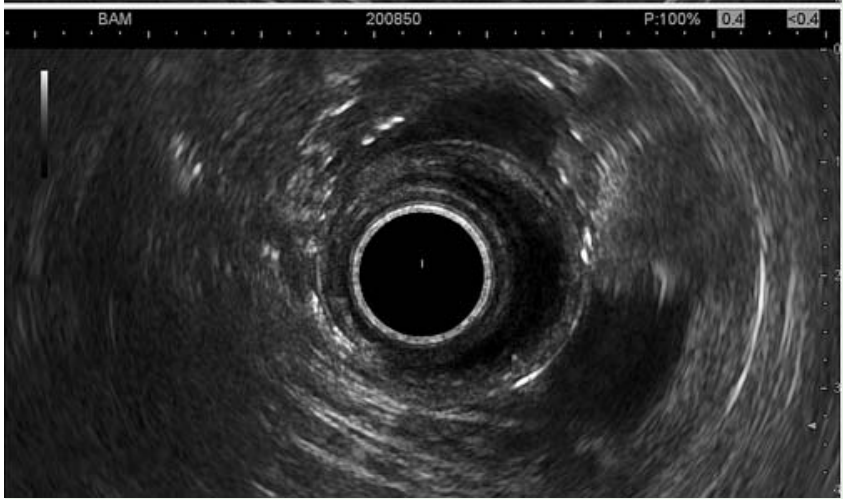

PCC is an uncommon condition in which submucosal and subserosal gas cysts are present within the bowel wall [1]. It can easily be mistaken for colonic polyps or submucosal tumors. Endoscopic resection of such lesions may be risky as it may cause colonic perforation and should therefore be avoided. Mucosal biopsies yield normal colonic epithelial cells. Complete cyst collapse can be achieved by puncturing the cysts with an injection needle.

CT scan can confirm the diagnosis, although the disadvantages of this investigation are radiation exposure and the

\section{Video 1}

Colonoscopy demonstrating multiple polypoidal lesions with normal overlying mucosa.

\section{Video 2}

Radial endoscopic ultrasound (EUS) demonstrating hyperechoic air pockets in the third layer of the colonic wall.
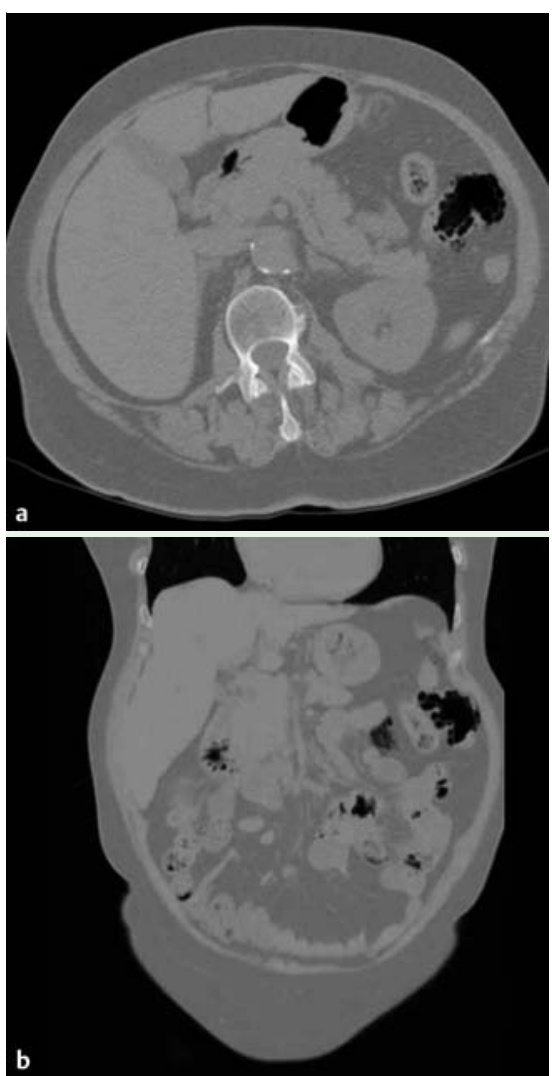

Fig. 3 Computed tomography (CT) scan showing air-filled cysts in the colonic wall in: a horizontal section; b coronal section. 
cost involved. Occasionally the air-filled cysts can be thought mistakenly to be intraluminal air and therefore can be missed by CT scanning [2]. Pneumatosis linearis, which is associated with bowel necrosis and ischemia, also presents with air in the layers of the intestinal wall. However, in this condition the mucosa is abnormal [3].

EUS shows multiple hyperechoic air pockets in layer three with acoustic shadowing that obscures the outer wall layers [4]. Its advantages are that it can be performed in the same session (as in our case) and there is no radiation exposure involved.

In summary, PCC can be easily mistaken for colonic polyps and EUS is a useful test to confirm the condition when it is suspected during colonoscopy.

Endoscopy_UCTN_Code_CCL_1AD_2AJ

Competing interests: None
Khaled Bamakhrama ${ }^{1}$, Luka Abdulhady ${ }^{2}$, Peter Vilmann ${ }^{1}$

${ }^{1}$ Gastroenterology Unit Endoscopy section, Copenhagen University Hospital Herlev, Denmark

${ }^{2}$ Department of Radiology, Copenhagen University Hospital Herlev, Denmark

\section{References}

1 Sleisenger MH, Fordtran JS. Gastrointestinal and liver diseases. 9th edn. Philadelphia: Saunders Elsevier; 2010

2 Bansal R, Bude R, Nostrant TT et al. Diagnosis of colonic pneumatosis cystoides intestinalis by endosonography. Gastrointest Endosc 1995; 42: 90 - 93

3 Ho LM, Paulson EK, Thompson WM. Pneumatosis intestinalis in adult: benign to lifethreatening causes. AJR 2007; 188: 16041613

4 Chang Y-T, Chang M-C, Wei S-C et al. Pneumatosis cystoides coli. Gastrointest Endosc 2006; 64: 820-821

\section{Bibliography}

DOI http://dx.doi.org/

10.1055/s-0034-1365152

Endoscopy 2014; 46: E195-E196

(c) Georg Thieme Verlag KG

Stuttgart · New York

ISSN 0013-726X

\section{Corresponding author}

Khaled Ahmed M. Bamakhrama, MD

Rashid Hospital

Dubai

United Arab Emirates

khalidgit@gmail.com 